\title{
Histogenesis of Foetal Cerebellar Cortex
}

\author{
${ }^{1}$ Dr. D. Asha Latha, M.D; ${ }^{2}$ Dr.K. Deena Usha, M.D; ${ }^{3}$ Dr.G.V. Siva Prasad, \\ ${ }^{4}$ Dr. Ravindra kishore, ${ }^{5}$ Dr. K. Lakshmi Kumari. \\ 1,2,3,4,5 Department of Anatomy, Andhra medical college, NRI Medical college, Visakhapatnam. RIMS,
} Srikakulam.

\begin{abstract}
The late multiplying, reservoir of stem cells is vulnerable to malignant transformation. The resulting tumour called a Medulloblastoma, is the commonest posterior fossa neoplasm in this age group. In the present study cerebellum specimens were collected from fifty aborted foetuses which were fixed in formalin. The age of foetuses were between $16 \mathrm{wks}$ to $30 \mathrm{wks}$ and 1 postnatal. The dissected specimens were preserved in $10 \%$ formalin and subjected to routine histological procedure for age related histogenesis and developmental anatomy. In present study we observed that major histogenesis occured during the $16^{\text {th }}$ week as single external granular layer which became 2 layered at 20 weeks and 3 layered at 26 weeks.
\end{abstract}

Keywords: Cerebellum, folia, cortex, external granular layer, molecular layer, Purkinje layer.

\section{Introduction}

The cortex of cerebellum consists of 3 distinct layers. The granular layer, a layer of Purkinje cells and the molecular layer on the surface as seen in adults. In the embryonic life the sub ventricular zone forms at the edge of the rhombic lip. Its cells then migrate over the outermost surface of the entire cerebellum multiplying as they go, to form a transient embryonic structure containing incredibly numerous tiny cells. This layer is called, not germinal matrix, as in the forebrain, but as external granular layer. Neurons in the external granular layer continue cell division longer than the other neurons in other parts of the brain. This leads to the tumour development. The price, removal of cerebellum is high, that the children often develop ordinary locomotion and posture, but they forever lose their potential for unconscious motor learning - most of them will never be able to ride a bicycle or knit a sweater.

\section{Material And Methods}

A total of 50 formalin preserved foetuses were obtained from department o f OBG, King George Hospital, Andhra Medical College. They were 16 weeks to 40 weeks of gestational age calculated by crown rump length. The cerebellums were collected by the opening of cranial cavity by routine dissection method. The specimens were characterised into 16wks, 20wks, 24wks, 26wks, $28 \mathrm{wks}, 30 \mathrm{wks}$, 34wks, 36wks, $40 \mathrm{wks}$, adult. Special staining methods were used apart from routine Haematoxylin and Eosin like Holmes silver nitrate. The sections were observed under 40,100 and 400 magnifications. The study was conducted under following heads: External Granular Layer( EGL) :- width of the layer in various age groups, types of cells, shape of the cells, the direction of axons. Molecular layer :- width.

Purkinje cell layer :- width, vertical and transverse diameter of cell, shape of cells, direction of dendrites and axons.

Internal granular layer(IGL):- shape of cells, direction of dendrites and width of the layer. These are all studied under various age groups.

\section{Results}

In $\mathrm{H} \& \mathrm{E}$ staining the appearance of whole cortex was found to be uniform. The elements had a precise geometric order in all planes in individual folia. The cortex composed of strata

1. Outer External granular layer.

2. Molecular layer

3. Purkinje layer

4. Internal granular layer.

16wks :- The outer surface of the cerebellar plate is formed by marginal zone. It consists of dense layer of cells migrating along meningeal surface and EGL or Orbesteiner's layer. The width is 50 microns image 1

20 wks:- Cortex shows EGL and molecular and IGL. The Purkinje cells are appreciable and multi cellular arranged in the form of clusters beneath the External granular layer. The width of EGL is 53 microns and molecular layer 52 microns and IGL 160 microns. Image 2 
24wks :- The cortex shows EGL, ML, IGL. The Purkinje layer is 2 layered thick. Their thickness is given in table 1 Image 3

26wks :- the width of Purkinje cell layer is 30 microns and is multi cellular, present between Molecular layer and IGL. Table: 2 Image 4 :

28wks :- the width is given in table 1 Image: 5

30wks :- The Purkinje cells show defined flask shaped. The vertical and transverse diameter is 16 microns and 13 microns respectively.

The width of layers is EGL, ML, IGL are table 1 image

32wks:- The width of layers is EGL, ML, IGL are table 5

36wks :- the width is shown in table 1 Image 7

40wks :- The diameter is about 19.3 microns and 17.8 microns in vertical and transverse. It is shown in table 1 Image 8 .

Holme's Silver nitrate:- The purkinje cells are seen with dendrites Image 9.

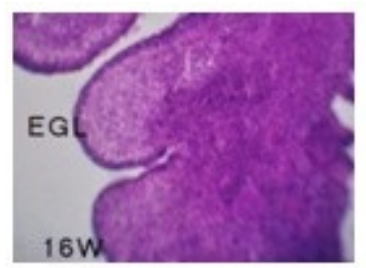

Image 1

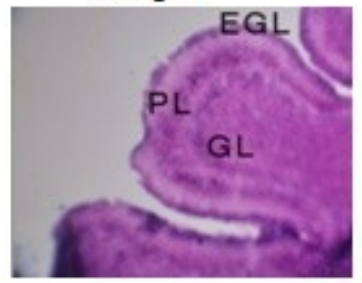

Image 3

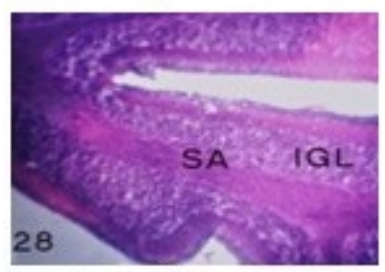

Image 5

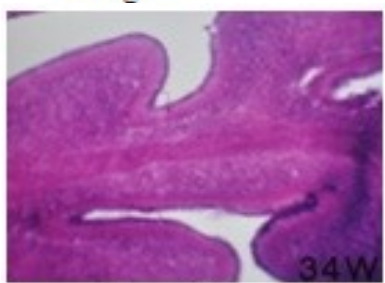

Image 7

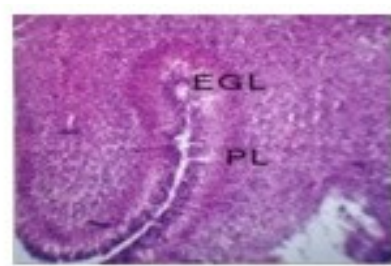

Image 2

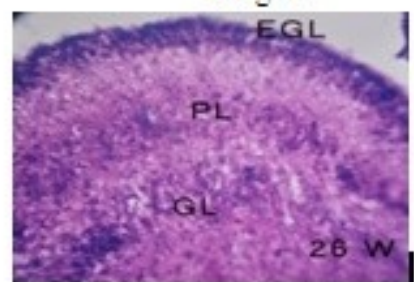

Image 4

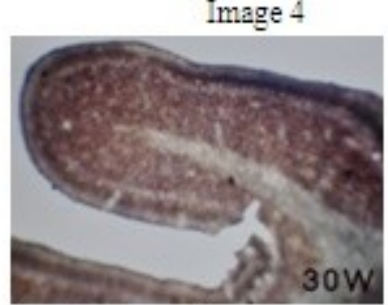

Image 6

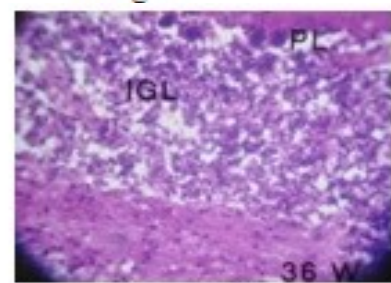

Image 8 High power

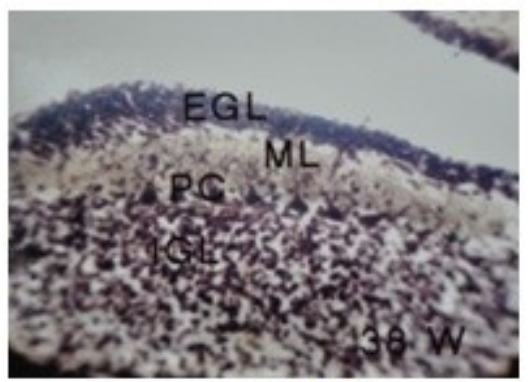

Image 9 
Size of EGL, ML, and IGL

Table -1

\begin{tabular}{|l|l|l|l|}
\hline Age in weeks & Width in microns & & \\
\hline & External granular layer & Molecular layer & Internal granular layer \\
\hline 16 wks & 50 & ----- & ------ \\
\hline 20 & 53 & 52 & 160 \\
\hline 24 & 60 & 60 & 172 \\
\hline 26 & 62 & 65 & 92 \\
\hline 28 & 45 & 70 & 204 \\
\hline 30 & 39 & 75 & 210 \\
\hline 32 & 37 & 78 & 225 \\
\hline 36 & 32 & 90 & 240 \\
\hline 40 & 30 & 90 & 290 \\
\hline
\end{tabular}

Size of Purkinje Cell in vertical and transverse diameters

Table 2

\begin{tabular}{|l|l|l|}
\hline Age in weeks & Vertical diameter & Transverse diameter \\
\hline 16 & ------ & ------- \\
\hline 20 & ------ & ----- \\
\hline 24 & 10 & 6 \\
\hline 26 & 12 & 8 \\
\hline 28 & 12 & 10 \\
\hline 30 & 16 & 13 \\
\hline 32 & 18 & 16 \\
\hline 36 & 18.6 & 16.8 \\
\hline 40 & 19.3 & 17.8 \\
\hline
\end{tabular}

\section{Discussion}

The histological section shows the EGL arising from anterior rhombic lip of the developing brainstem cells. When EGL cells undergo their final mitosis they grow their axons and translocate their cell bodies in different cell directions. These cells grow parallel to one another and this layer is superficial to the Purkinje cell bodies which are already in place and this layer is superficial to Purkinje cell bodies. This layer constitutes of parallel fibres of granule cells and becomes molecular layer. The granule cells migrate from EGL inwards by passing the Purkinje cell bodies which are already in place and this leads to formation of IGL. They use the preexisting radial Glial fibres as guide wires for migration.

The EGL gradually decreases as the age of foetus increases and this descent is rapid and is completely lost after postnatal $9^{\text {th }}$ month. The diameter of Purkinje cell increases as age advances.

\section{Conclusions}

The histology showed EGL, ML, IGL and Purkinje cell layer. The width of EGL at 16wks is 50 microns, ML and IGL are not yet seen. The width at 20 wks show all the three layers. The width shows 10-30 microns range for $5^{\text {th }}$ month to full term. The width of ML is $40-90$ microns and increases with age.

The width of IGL is 160-290 microns.

Vertical diameter of purkinje cell ranged from $16-19.3$ microns. The transverse diameter is $13-17.8$ microns.

In Holmes silver nitrate method - the dendrites of purkinje cells their flask shape, dendrites of basket cells can be appreciated.

The type 2 satellite cells are seen at 36-38wks. The type 1 Satellite cells are seen in $36 w k s$. Th e Granule cells can be seen in $20 \mathrm{wks}$ and they are bipolar.

\section{Referances}

[1]. Altman A,Bayer SA 1977,Time of origin and distribution of new cell type in the cerebellar cortex of rats. Exp Brain Res 29;265274.

[2]. Ari' 'ens kappers, Huber CG and Crosby E 1936. The comparative anatomy of the nervous system of vertebrates, including man Vol: Mac millanCo, Newyork Pp:696-700; 775-790

[3]. Saddler TW 2000 Langman's Medical Embryology $8^{\text {th }}$ edpp: 430.

[4]. Williams PL etal 1995 Grays Anatomy In: Nervous system Churchill Livingstone, London 38 ${ }^{\text {th }}$ ed pp: 240-243: 1028-1065.

[5]. Development and Death of EGL cells. Journal of Neuro science,ACcer mars 19/2012.

[6]. Muller F, O Rahilly R (1990) " The human Brain at stages (21-23) with particular reference to the cerebral cortical plate and to the development of the cerebellum” Anat Embrol (Berl) 182(4); 375-400 doi.10;1007/BF02433497.

[7]. Ros. H. Sachdev RN, Yu,Y,Sestan N, Mc Cormik DA (2009) Neocortical networks. 